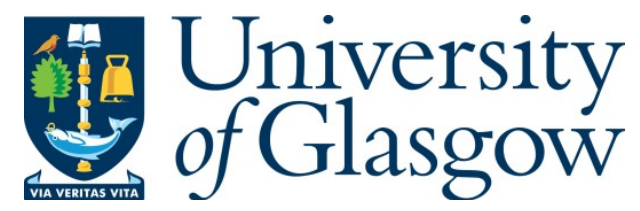

Mansouri, D., McMillan, D. C., McIlveen, E., Crighton, E. M., Morrison, D., and Horgan, P. G. (2016) A comparison of tumour and host prognostic factors in screen-detected versus non screen-detected colorectal cancer: a contemporaneous study. Colorectal Disease, 18(10), pp. 967-975.

(doi:10.1111/codi.13295)

This is the author's final accepted version.

There may be differences between this version and the published version. You are advised to consult the publisher's version if you wish to cite from it.

http://eprints.gla.ac.uk/116489/

Deposited on: 15 March 2016

Enlighten - Research publications by members of the University of Glasgow http://eprints.gla.ac.uk 
Received Date : 15-Oct-2015

Revised Date : 15-Dec-2015

Accepted Date : 24-Dec-2015

Article type : Original Article

Corresponding Author E-Mail Id: David.Mansouri@glasgow.ac.uk

\section{A comparison of tumour and host prognostic factors in screen-detected versus non screen-detected colorectal cancer: a contemporaneous study}

David Mansouri MBChB (Clinical Lecturer Surgery)) ${ }^{1}$, Donald C McMillan PhD (Professor of Surgical Science) ${ }^{1}$, Erin Mcllveen MBChB (Speciality Registrar Surgery) ${ }^{1}$, Emilia M Crighton MD (Consultant Public Health)2 ${ }^{2}$, David S Morrison MD (Consultant Public Health) ${ }^{3}$, Paul G Horgan PhD (Professor of Surgery) ${ }^{1}$

1. Academic Unit of Colorectal Surgery, University of Glasgow, Glasgow Royal Infirmary, Glasgow, G31 2ER

2. Department of Public Health Screening Unit, NHS Greater Glasgow \& Clyde, West House, Gartnavel Royal Hospital, Glasgow, G12 0XH

3. West of Scotland Cancer Surveillance Unit, Lillybank Gardens, Glasgow

\section{Correspondence to:}

Mr David Mansouri

Academic Unit of Colorectal Surgery,

College of Medical, Veterinary and Life Sciences,

University of Glasgow

Rm 2.57 New Lister Building

Glasgow Royal Infirmary

10-16 Alexandra Parade

G31 2ER

This article has been accepted for publication and undergone full peer review but has not been through the copyediting, typesetting, pagination and proofreading process which may lead to differences between this version and the Version of Record. Please cite this article as an 'Accepted Article', doi: 10.1111/codi.13295

This article is protected by copyright. All rights reserved. 


\section{Conflict of interest statement}

The authors have no conflicts of interest to disclose.

\section{Author Contributions}

DM: study concept and design; acquisition of data; analysis and interpretation of data; drafting of the manuscript; critical revision of the manuscript for important intellectual content; statistical analysis. DCM: study concept and design; analysis and interpretation of data; critical revision of the manuscript for important intellectual content; statistical analysis. EM: acquisition of data; analysis and interpretation of data; drafting of the manuscript; statistical analysis. EMC: study concept and design; acquisition of data; critical revision of the manuscript for important intellectual content; technical, or material support. DSM: study concept and design; acquisition of data; analysis and interpretation of data; critical revision of the manuscript for important intellectual content; statistical analysis. PGH: study concept and design; critical revision of the manuscript for important intellectual content; study supervision.

\section{ABSTRACT}

Aim: In addition to TNM stage, there are adverse tumour and host factors, such as venous invasion and the presence of an elevated systemic inflammatory response (SIR) that influence the outcome in colorectal cancer. The present study aimed to examine how these factors varied in screen detected (SD) and non-screen detected tumours (NSD).

Method: Prospectively maintained databases of the prevalence round of a biennial population FOBt screening programme and a regional cancer audit database were analysed. Interval cancers (INT) were defined as cancers identified within two years of a negative screening test.

Results: Of the 395097 invited, 204535 (52\%) responded, 6159 (3\%) tested positive, and 421 (9\%) had cancer detected. From this cohort, a further 708 (63\%) NSD patients were identified (468 (65\%) non-responders, 182 (25\%) INT cancers and 58 (10\%) did not attend or did not have cancer diagnosed at colonoscopy). Comparing SD and NSD patients, SD patients were more likely to be male, and have a tumour with a lower Dukes stage (both $p<0.05$ ). On stage-by-stage analysis, SD patients had less evidence of an elevated SIR $(\mathrm{p}<0.05)$. Both the presence of venous invasion ( $p=0.761)$ and an elevated SIR ( $p=0.059)$ were similar between those with INT cancers and in those that arose in non-responders.

Conclusion: Independent of TNM stage, SD tumours have more favourable host prognostic factors than NSD tumours. There is no evidence that INT cancers are biologically more aggressive than those that develop in the rest of the population and hence are likely to be due to limitations of screening in its current format.

This article is protected by copyright. All rights reserved. 
Keywords: colorectal cancer screening, gFOBt, FIT, tumour factors, host systemic inflammation

\section{What does this paper add to the literature?}

In addition to having tumours of an earlier stage, patients with tumours detected through the FOBt screening programme have improved host prognostic factors, in terms of a lower preoperative systemic inflammation response, than patients with non screen-detected disease.

\section{INTRODUCTION}

The outcome following a diagnosis of colorectal cancer is directly related to the stage at diagnosis, with over $90 \%$ of those who undergo resection for Stage 1 disease alive at 5 -years compared with less than $50 \%$ for Stage III disease [1]. Independent of the TNM stage, however,there are other additional adverse features of the tumour itself and the patient, the so called 'host', that have been shown to predict a worse outcome. For example, the presence of venous invasion or poor differentiation, are now used in clinical practice to help identify patients with more aggressive Stage II disease who are at a higher risk and hence may benefit from adjuvant chemotherapy [2-4]. It has been argued recently that the combination of T-stage and venous invasion is superior to the traditional TNM stage in predicting outcome in node negative disease [5].

There is now a wealth of evidence that the presence of an elevated host systemic inflammatory response (SIR) is an independent negative prognostic factor in patients with cancer [6]. The SIR can be assessed routinely with standard bedside tests such as C-reactive protein (CRP) or the neutrophil to lymphocyte ratio (NLR) [7-11]. In the case of colorectal cancer specifically, those with an elevated pre-operative SIR have a poorer outcome independent of the TNM stage $[7,12]$.

This article is protected by copyright. All rights reserved. 
Screening for colorectal cancer using the guaiac-based faecal occult blood test (gFOBt) increases the number of early stage cancers diagnosed and reduces cancer specific mortality [13-15]. In addition, there is increasing evidence that screening using the faecal immunochemical test (FIT) may have improved sensitivity over gFOBt [16-18]. This has lead to the development of the Scottish Bowel Screening Programme (SBoSP), which is a combined gFOBt/FIT population based screening programme [19]. This has been found to detect a large number of early stage tumours, although interval cancers (tumours that develop within two years of a negative screening test) do develop [20].

In assessing the efficacy of colorectal cancer screening, previous work has examined differences between screen-detected and non screen-detected disease and has shown improved survival in screen-detected patients [21-27]. Such analysis has, however, focused on the stage and site of tumours and only one such study has included detailed analysis of adverse tumour factors beyond TNM stage that are of independent prognostic significance [21]. Furthermore, to date, no previous studies have included assessment of the pre-operative host systemic inflammatory response within the context of a colorectal cancer screening programme. The aim of the present study was to examine the efficacy of the first round of a population based gFOBt/FIT colorectal cancer screening programme in our geographical area with regard to cancer detection rates, and to compare and contrast adverse tumour and host prognostic factors in screen-detected and non screen-detected colorectal cancer.

\section{METHOD}

Details of all individuals who were invited to the first round of the SBoSP during April 2009 to the end of March 2011 in NHS Greater Glasgow \& Clyde (NHS GG\&C) were extracted from the prospectively maintained NHS GG\&C Bowel Screening IT System (original date of extraction January 2012, updated April 2014). They included all individuals, in NHS GGG\&C, aged between 50 and 74 years, who were registered with a General Practitioner. Methodology data on the screening algorithm and processing of samples of the SBoSP have been described previously

This article is protected by copyright. All rights reserved. 
[19]. Briefly, individuals are sent a pre-invitation letter and then a gFOBt kit (hemascreen, Immunostics, Ocean, New Jersey, USA, supplied by Alpha Laboratories, Eastleigh, Hampshire, $\mathrm{UK}$ ) and referred for colonoscopy if this is returned and is strongly positive ( $>5$ of 6 windows positive). In the case of a weakly positive gFOBt (1-4 of 6 windows positive) or spoiled or untestable kit a confirmatory FIT kit (hema-screen SPECIFIC, Immunostics, Ocean, New Jersey, USA, supplied by Alpha Laboratories, Eastleigh, Hampshire, UK) is sent. Data were extracted on individuals invited for screening,including the combined gFOBt/FIT result and the uptake and result of colonoscopy.

All individuals invited for screening in this first round were cross-referenced with the prospectively maintained West of Scotland Colorectal Cancer Managed Clinical Network (MCN) dataset and also linked to the Scottish Cancer Registry (SMR06). This allowed the identification of any patient with a diagnosis of colorectal cancer. As screening invitations were biennial, patients with cancer detected more than 720 days after screening invite were excluded. Patients with colorectal cancer were then categorised as having screen-detected disease (SD), or non screen-detected disease (NSD). NSD patients were then further characterised as nonresponders to the screening invitation (NR), having an interval cancer detected following a negative gFOBt/FIT (INT), having a cancer in a patient who tested positive but did not attend for colonoscopy (NA) or having a cancer in a patient who did not have cancer detected at colonoscopy following a positive screening test (CN). Patients who had an initially suspicious adenoma detected through screening and as a result of subsequent investigations had colorectal cancer detected within six months of the invitation for screening were termed SD.

Individual patient records were then interrogated on a case-by-case basis to identify further clinicopathological variables for analysis. Tumours were staged according to the conventional tumour node metastasis (TNM) classification (5th Edition) [28]. Polyp cancers that were managed endoscopically, and did not undergo formal resection were assumed to be node negative and classified as TNM Stage I. Additional high-risk tumour features, such as poor

This article is protected by copyright. All rights reserved. 
differentiation, the presence of venous invasion, peritoneal involvement and margin involvement, were identified from pathology reports.

Both the absolute neutrophil count and the neutrophil to lymphocyte ratio (NLR) were used as markers of the pre-operative SIR and were obtained from pre-operative blood results taken most immediately and not more than six weeks before surgery. A previously validated threshold of an NLR of $>5$ was used as evidence of a significantly elevated SIR [9]. An absolute neutrophil level greater than $7.5 \times 10^{9}$ /litre was defined as elevated based on local laboratory guidelines.

Permission for the study was granted by the Caldicott Guardian of the Screening dataset and by the West of Scotland Colorectal Cancer MCN Management group. Data were stored and analysed in an anonymised manner.

\section{Statistical analysis}

Associations between categorical variables were examined using the $\chi^{2}$ test. For ordered variables with multiple categories the $\chi^{2}$ test for a linear trend was used. Fisher's exact test was used for assessing associations where the expected individual cell counts were less than 5 . A value of $\mathrm{p}<0.05$ was considered statistically significant. Statistical analysis was performed using SPSS software (SPSS Inc., Chicago, IL, USA)

\section{RESULTS}

From April 2009 to March 2011, representing the first complete round of screening in NHS GG\&C, 395097 individuals were invited to participate, 204535 (52\%) responded and 6159 (3.0\%) tested positive. Of those who tested positive, 4797 (78\%) individuals proceeded to colonoscopy and 421 patients had cancer detected (SD) (Figure 1). These figures differ slightly 
from previously published work by our group due to updating of the data within the Bowel Screening IT System [29]. After cross-referencing with MCN and SMR06 datasets, 708 patients with NSD colorectal cancer were identified (468 (65\%) patients NR; 182 (25\%) patients INT, 43 (6\%) patients NA; $15(2 \%)$ patients $\mathrm{CN}$ ). This generated an estimated sensitivity and specificity of the first round of the gFOBt/FIT screening test, for the detection of cancer of $72.4 \%$ and 97.2\% (Supplementary Table 1).

\section{Comparison of Screen-detected and Non Screen-detected Colorectal cancer}

SD patients were more likely than NSD patients to be male $(\mathrm{p}=0.002)$, have more distal disease $(p=0.003)$, which was of an earlier stage $(p<0.001)$ and were more likely to undergo a procedure with a curative intent $(\mathrm{p}<0.001)$ (Table 1). In those undergoing a curative procedure, SD patients had a less advanced T-stage and less evidence of venous invasion, peritoneal involvement and margin involvement $(\mathrm{p}<0.05)$. They also had less evidence of an elevated preoperative SIR judged by the NLR and the absolute neutrophil count (Table 2). A stage by stage analysis of factors was then carried out (Supplementary Table 2). Patients with SD tumours had less evidence of an elevated SIR in stage II and III disease. There was no significant difference in venous invasion rates between SD and NSD tumours in all four stages (Supplementary Table 2).

\section{Comparison of Interval and Screen-detected Cancers}

INT patients were more likely than SD patients to be female $(\mathrm{p}<0.001)$, have more proximal disease $(\mathrm{p}<0.001)$, have more advanced disease $(\mathrm{p}<0.001)$ and less likely to be managed with a curative intent $(\mathrm{p}<0.001)$ (Table 3$)$. In addition, they were more likely to have adverse prognostic factors such as venous invasion $(\mathrm{p}=0.026)$ and an elevated pre-operative SIR $(p=0.025)$ (Table 3). On stage by stage analysis, however, these differences failed to retain statistical significance. In particular, venous invasion rates were similar in Stage 1 (17\% INT vs $25 \%$ SD, $\mathrm{p}=0.344$ ), Stage II (57\% INT vs $47 \%$ SD, $\mathrm{p}=0.272$ ) and Stage III (71\% INT vs $70 \%$ SD, $\mathrm{p}=0.970$ ) disease.

This article is protected by copyright. All rights reserved. 


\section{Comparison of Interval and Non-Responder Cancers}

INT patients were more likely than NR patients to be female $(\mathrm{p}=0.034)$ (Table 4). There was trend towards INT patients having less advanced $(\mathrm{p}=0.052)$ and more proximal disease $(\mathrm{p}=0.090)$ but this did not reach significance at the $5 \%$ level. When patients who were treated with a curative intent were examined, there was no difference in adverse pathological features between INT and NR patients. There was a trend for NR patients have an elevated preoperative SIR ( $p=0.059)$ compared with INT patients (Table 4).

\section{DISCUSSION}

The results of the present study provide a comprehensive analysis of the outcome from the first round of a stool-based colorectal cancer screening programme. It confirms previous studies that have found that screen-detected tumours are of an earlier stage than non screen-detected tumours and reports for the first time that individuals with screen-detected disease have more favourable host prognostic factors than those with non screen-detected disease.

Analysis of host factors, such as the presence of an elevated SIR has not previously been examined within the context of a colorectal cancer screening programme. In addition to inflammatory responses in the tumour micro-environment [30], systemic inflammatory responses are now recognised as a key hallmark of cancer [6]. In particular there is a wealth of evidence that host factors are associated with an adverse outcome in colorectal cancer including meta-analyses $[7,11]$. To date, however, their inclusion as a means of predicting outcome outside in the routine clinical setting has been patchy. In the present study the most readily available measure of the systemic inflammatory response, in the form of neutrophils and the neutrophil to lymphocyte ratio has been included [31,32]. This additional information adds to the level of detail available for the cohort and is a unique feature of this comprehensive analysis.

This article is protected by copyright. All rights reserved. 
It could be argued that the present study, showing that some adverse tumour prognostic factors are less prevalent in SD tumours than in NSD tumours, is evidence for the effect of length-time bias where the identification of indolent slow growing tumours artificially improves cancerspecific survival by detecting those who have a longer pre-clinical phase [33]. When, however, adjustment is made for stage, the two key features in keeping with phenotypically more aggressive tumours, venous invasion and poor differentiation, do not achieve statistical significance. Furthermore, it has previously been postulated that INT tumours not only represent tumours missed by the screening test itself but may be more aggressive if they develop within the screening interval [20]. Examining in detail tumour and host prognostic factors in INT compared with NR tumours provides evidence to refute this hypothesis. There was no evidence of adverse tumour features in the INT group when compared with the NR group in the present study. Indeed, there was a trend for NR patients to have evidence of a higher host SIR. Therefore, the conclusion that can be drawn from the present study is that the inherent biological characteristics of SD tumours do not differ from those of NSD disease.

There were higher numbers of cancers in both the NA and CN groups than initially expected. On further investigation, however, it became apparent that a substantial proportion of the NA patients (40\%, data not presented), were already under investigation for colorectal symptoms and had sent back the screening test in the midst of undergoing non-screening investigations. Also, of the 15 patients who were CN, 12 (80\%) (data not presented) had polyps detected at colonoscopy and hence were undergoing follow-up. For the purposes of the present study, a cancer diagnosis outwith six months of initial colonoscopy was defined as NSD, but it may be argued that these patients would not have been detected at that time had they not participated in screening. Nevertheless, the 15 patients who were $\mathrm{CN}$ represent a post-colonoscopy colorectal cancer rate of 3\% which compares favourably with other studies that have examined this outwith screening programmes which have provided rates of $2-8 \%$, albeit with longer (3 to 5 year) follow-up [34-36]. The majority of post-colonoscopy colorectal cancers are thought to arise through procedural factors such as missed lesions and inadequate examination [35]. The

This article is protected by copyright. All rights reserved. 
SBoSP has tight quality control on all colonoscopists requiring to be Joint Advisory Group (JAG) accredited and have a greater than $90 \%$ caecal intubation rate [37]. It was not in the scope of the present study to examine colonoscopy quality indexes in more detail, but the low rate of post-colonoscopy colorectal cancer was reassuring.

\section{Strengths and weaknesses}

The main strengths of the present study include the comprehensive and detailed dataset. Case notes were examined on a case-by-case basis allowing for more detailed analysis of clinicopathological factors at a depth that has not previously been undertaken. For example, in the present study after case note review, only $2 \%$ of tumours remained unstaged compared with $25 \%$ in a previous study using population databases [23]. In addition, we have included data from non-responders, which have been absent from other studies, and by utilising regional and national cancer registry datasets we have comprehensively captured those with NSD disease from corroborative sources.

The main limitation of the study is the fact that this is a prevalence round of a screening programme and as such these results may not be applicable in subsequent rounds. This is important when analysing data presented regarding sensitivity and specificity. A further possible limitation was that all NSD tumours were taken as the main comparison group. Comparing INT to SD tumours might have been a better measure of the impact of screen detection. Nevertheless the present study represents a population setting whereby compliance to the screening programme was just over $50 \%$. Therefore to exclude NR tumours, would be to exclude from the study a large proportion of the population invited for screening. A subanalysis comparing SD with INT tumours was undertaken and no difference in prognostic factors was elicited when adjusted for stage. Such subanalyses will by definition be limited by reduced numbers and hence power and additional work is required to examine these findings further. Finally, our measure of the SIR was by NLR and not the modified Glasgow Prognostic Score

This article is protected by copyright. All rights reserved. 
(mGPS), which has been shown to be a more sensitive measure of host inflammation with regard outcome [8] , but this is a retrospective study, and C-reactive protein required for calculating mGPS, was not routinely measured pre-operatively in all hospitals during this timeframe.

In conclusion, the present study reports that patients with SD tumours, independent of stage, had more favourable host prognostic factors than patients with NSD tumours. There was, however, no difference in adverse tumour features associated with an aggressive tumour phenotype. In addition, INT cancers did not appear to have more aggressive features than tumours that developed in the rest of the population and hence were more likely to arise as a result of the limitations of the testing algorithm itself rather than represent biologically more aggressive tumours. Further work, identifying a more sensitive test is required to increase the number of tumours that are detected through screening and hence to improve the outcome in colorectal cancer.

\section{Acknowledgments}

The authors wish to thank the members of the West of Scotland Colorectal Cancer Managed Clinical Network. In addition we would like to thank Annette Little, Paul Burton and Billy Sloan for their help with data extraction and processing.

\section{REFERENCES}

1. Cancer Research UK. Available at www.cancerresearchuk.org

2. Compton, C. C., Fielding L. P., Burgart L. J., Conley B., Cooper H. S., Hamilton S. R., Hammond M. E., Henson D. E., Hutter R. V., Nagle R. B., Nielsen M. L., Sargent D. J., Taylor C. R., Welton M. and Willett C. (2000) Prognostic factors in colorectal cancer. College of American Pathologists Consensus Statement 1999. Arch Pathol Lab Med 124(7): 979-994.

This article is protected by copyright. All rights reserved. 
3. Petersen, V. C., Baxter K. J., Love S. B. and Shepherd N. A. (2002) Identification of objective pathological prognostic determinants and models of prognosis in Dukes' B colon cancer. Gut 51(1): 65-69.

4. Figueredo, A., Coombes M. E. and Mukherjee S. (2008) Adjuvant therapy for completely resected stage II colon cancer. Cochrane Database Syst Rev (3): CD005390.5.

5. Roxburgh, C. S., McMillan D. C., Richards C. H., Atwan M., Anderson J. H., Harvey T., Horgan P. G. and Foulis A. K. (2014) The clinical utility of the combination of T stage and venous invasion to predict survival in patients undergoing surgery for colorectal cancer. Ann Surg 259(6): 1156-1165.

6. McAllister S.S. and Weinberg R.A. (2014) The tumour-induced systemic environment as a critical regulator of cancer progression and metastasis. Nature cell biology 16(8):717-27

7. Roxburgh C.S. and McMillan D.C. (2010) Role of systemic inflammatory response in predicting survival in patients with primary operable cancer. Future oncology 6(1):149-63

8. Proctor, M. J., Morrison D. S., Talwar D., Balmer S. M., Fletcher C. D., O'Reilly D. S., Foulis A. K., Horgan P. G. and McMillan D. C. (2011) A comparison of inflammation-based prognostic scores in patients with cancer. A Glasgow Inflammation Outcome Study. Eur J Cancer 47(17): 2633-2641.

9. Walsh, S. R., Cook E. J., Goulder F.,. Justin T. A and Keeling N. J. (2005) Neutrophillymphocyte ratio as a prognostic factor in colorectal cancer. J Surg Oncol 91(3): 181-184.

10. Ishizuka, M., Nagata H., Takagi K., Horie T and Kubota K. (2007) Inflammation-based prognostic score is a novel predictor of postoperative outcome in patients with colorectal cancer. Ann Surg 246(6): 1047-1051.

11. Li, M. X., Liu X. M., Zhang X. F., Zhang J. F., Wang W. L., Zhu Y., Dong J., Cheng J. W., Liu Z. W., Ma L. and Lv Y. (2014) Prognostic role of neutrophil-to-lymphocyte ratio in colorectal cancer: a systematic review and meta-analysis. Int J Cancer 134(10): 2403-2413.

This article is protected by copyright. All rights reserved. 
12. Crozier, J. E., McKee R. F., McArdle C. S., Angerson W. J., Anderson J. H., Horgan P. G. and McMillan D. C. (2006) The presence of a systemic inflammatory response predicts poorer survival in patients receiving adjuvant 5-FU chemotherapy following potentially curative resection for colorectal cancer. Br J Cancer 94(12): 1833-1836.

13. Hardcastle, J. D., Chamberlain J. O., Robinson M. H., Moss S. M., Amar S. S., Balfour T. W., James P. D. and Mangham C. M. (1996) Randomised controlled trial of faecal-occult-blood screening for colorectal cancer. Lancet 348(9040): 1472-1477.

14. Kronborg, O., Fenger C., Olsen J., Jorgensen O. D. and Sondergaard O. (1996) Randomised study of screening for colorectal cancer with faecal-occult-blood test. Lancet 348(9040): 14671471.

15. Hewitson, P., Glasziou P., Irwig L., Towler B. and Watson E. (2007) Screening for colorectal cancer using the faecal occult blood test, Hemoccult. Cochrane Database Syst Rev (1): CD001216.

16. Hol, L., Wilschut J. A., van Ballegooijen M., van Vuuren A. J., van der Valk H., Reijerink J. C., van der Togt A. C., Kuipers E. J., Habbema J. D. and van Leerdam M. E. (2009) Screening for colorectal cancer: random comparison of guaiac and immunochemical faecal occult blood testing at different cut-off levels. Br J Cancer 100(7): 1103-1110.

17. Parra-Blanco, A., Gimeno-Garcia A. Z., Quintero E., Nicolas D., Moreno S. G., Jimenez A., Hernandez-Guerra M., Carrillo-Palau M., Eishi Y.and Lopez-Bastida J. (2010) Diagnostic accuracy of immunochemical versus guaiac faecal occult blood tests for colorectal cancer screening. J Gastroenterol 45(7): 703-712.

18. Guittet, L., Bouvier V., Mariotte N.,. Vallee J. P, Arsene D., Boutreux S., Tichet J. and Launoy G. (2007) Comparison of a guaiac based and an immunochemical faecal occult blood test in screening for colorectal cancer in a general average risk population. Gut 56(2): 210-214.

19. Fraser, C. G., Digby J., McDonald P. J., Strachan J. A., Carey F. A. and Steele R. J. (2012) Experience with a two-tier reflex gFOBT/FIT strategy in a national bowel screening programme. J Med Screen 19(1): 8-13.

This article is protected by copyright. All rights reserved. 
20. Steele, R. J., McClements P., Watling C., Libby G., Weller D., Brewster D. H., Black R., Carey F. A. and Fraser C. G. (2012) Interval cancers in a FOBT-based colorectal cancer population screening programme: implications for stage, gender and tumour site. Gut 61(4): 576-581.

21. Roxburgh C., McTaggart F., Balsitis M. and Diament R. (2012) The impact of the bowel screening programme on the diagnosis of colorectal cancer in Ayrshire and Arran. Colorectal Dis 15(1):34-41

22. Mackay, C. D., Ramsay G., Rafferty A. and Loudon M. A. (2012) Does the location of colorectal carcinoma differ between screened and unscreened populations? Colorectal Dis 14(10): e689-691.

23. Morris, E. J., Whitehouse L. E., Farrell T., Nickerson C., Thomas J. D., Quirke P., Rutter M. D., Rees C., Finan P. J., Wilkinson J. R. and Patnick J. (2012) A retrospective observational study examining the characteristics and outcomes of tumours diagnosed within and without of the English NHS Bowel Cancer Screening Programme. Br J Cancer 107(5):757-64

24. Pande R., Froggatt P., Baragwanath P. and Harmston C. (2013) Survival outcome of patients with screening versus symptomatically detected colorectal cancers. Colorectal Dis 15(1):74-9

25. Libby, G., Brewster D. H., McClements P. L., Carey F. A., Black R. J., Birrell J., Fraser C. G. and Steele R. J. (2012) The impact of population-based faecal occult blood test screening on colorectal cancer mortality: a matched cohort study. Br J Cancer 107(2): 255-259.

26. Courtney E., Chong D., Tighe R., Easterbrook J., Stebbings W. and Hernon J. (2013) Screen-detected colorectal cancers show improved cancer specific survival when compared with cancers diagnosed via the two-week suspected colorectal cancer referral guidelines. Colorectal Dis 15(2):177-82

27. Gill M.D., Bramble M.G., Rees C.J., Lee T. J., Bradburn D. M. and Mills S. J. (2012) Comparison of screen-detected and interval colorectal cancers in the Bowel Cancer Screening Programme. Br J Cancer 107(3):417-21

28. Sobin L.H. and Fleming I.D. TNM Classification of Malignant Tumors, fifth edition (1997). Union Internationale Contre le Cancer and the American Joint Committee on Cancer. Cancer 80(9):1803-4

This article is protected by copyright. All rights reserved. 
29. Mansouri D., McMillan D.C., Grant Y., Crighton E.M. and Horgan P.G. (2013) The impact of age, sex and socioeconomic deprivation on outcomes in a colorectal cancer screening programme. PloS one 8(6):e66063

30. Hanahan D. and Weinberg R.A. (2011) Hallmarks of Cancer: the next generation. Cell 144(5):646-74

31. Watt D.G., Martin J.C., Park J.H., Horgan P.G. and McMillan D.C. (2015) Neutrophil count is the most important prognostic component of the differential white cell count in patients undergoing elective surgery for colorectal cancer. Am J Surg 210(1):24-30

32. Guthrie G.J., Charles K.A., Roxburgh C.S., Horgan P.G., McMillan D.C. and Clarke S.J. (2013) The systemic inflammation-based neutrophil-lymphocyte ratio: experience in patients with cancer. Crit Rev Oncol Hematol 88(1):218-30

33. Kay B.R. and Witte D.L. (1991) The impact of cancer biology, lead time bias, and length bias in the debate about cancer screening tests. J Insur Med 23(2):102-4

34. Singh, H., Nugent Z., Demers A. A. and Bernstein C. N. (2010) Rate and predictors of early/missed colorectal cancers after colonoscopy in Manitoba: a population-based study. Am J Gastroenterol 105(12): 2588-2596.

35. Bressler, B., Paszat L. F., Chen Z., Rothwell D. M., Vinden C. and Rabeneck L. (2007) Rates of new or missed colorectal cancers after colonoscopy and their risk factors: a population-based analysis. Gastroenterology 132(1): 96-102.

36. le Clercq, C. M., Bouwens M. W., Rondagh E. J., Bakker C. M., Keulen E. T., de Ridder R. J., Winkens B., Masclee A. A. and Sanduleanu S. (2014) Postcolonoscopy colorectal cancers are preventable: a population-based study. Gut 63(6): 957-963.

37. NHS Quality Improvement Scotland Clinical Standards. Available at http://www.healthcareimprovementscotland.org/previous_resources/standards/bowel_screen ing_programme_clin.aspx. Bowel Screening Programme, 2007.

This article is protected by copyright. All rights reserved. 
Table 1: Baseline characteristics of Screen-detected and Non Screen-detected colorectal cancer (all patients)

\begin{tabular}{|c|c|c|c|c|}
\hline & \begin{tabular}{|c|} 
All \\
patients \\
$\mathbf{n}(\%)$
\end{tabular} & $\begin{array}{c}\begin{array}{c}\text { Screen- } \\
\text { detected }\end{array} \\
\text { n(\%) }\end{array}$ & $\begin{array}{c}\begin{array}{c}\text { Non Screen- } \\
\text { detected }\end{array} \\
\text { n(\%) }\end{array}$ & $\begin{array}{l}p \text { - } \\
\text { value }\end{array}$ \\
\hline & 1129 & 421 & 708 & \\
\hline \multicolumn{5}{|l|}{ Age } \\
\hline$<64$ & 437 (39) & $164(39)$ & $273(39)$ & \\
\hline $64-70$ & $300(27)$ & $114(27)$ & $186(26)$ & \\
\hline$>70$ & $392(35)$ & $143(34)$ & $249(35)$ & 0.762 \\
\hline \multicolumn{5}{|l|}{ Sex } \\
\hline Female & $447(40)$ & $142(34)$ & $305(43)$ & \\
\hline Male & $682(60)$ & $279(66)$ & $403(57)$ & 0.002 \\
\hline \multicolumn{5}{|l|}{ Site } \\
\hline $\begin{array}{l}\text { Proximal to splenic } \\
\text { flexure }\end{array}$ & $325(29)$ & $100(24)$ & $225(32)$ & \\
\hline Distal to splenic flexure & $795(71)$ & $321(76)$ & $474(67)$ & 0.003 \\
\hline Synchronous & $9(1)$ & 0 & $9(1)$ & \\
\hline \multicolumn{5}{|l|}{ TNM Stage } \\
\hline $\mathbf{I}$ & $318(28)$ & $191(45)$ & 127 (18) & \\
\hline II & $285(25)$ & $93(22)$ & $192(27)$ & \\
\hline III & $284(25)$ & $103(25)$ & $181(26)$ & \\
\hline IV & $220(20)$ & $28(7)$ & $192(27)$ & $<0.001$ \\
\hline Unstaged & $22(2)$ & $6(1)$ & $16(2)$ & \\
\hline
\end{tabular}

This article is protected by copyright. All rights reserved. 


\begin{tabular}{|c|c|c|c|c|}
\hline Management intent & & & & \\
\hline Curative procedure & $872(77)$ & $393(93)$ & $479(68)$ & \\
\hline Palliative procedure & $102(9)$ & $8(2)$ & $94(13)$ & \\
\hline No procedure & $155(14)$ & $20(5)$ & $135(19)$ & $<0.001$ \\
\hline
\end{tabular}

Table 2: Comparison of tumour and host prognostic factors between Screen-detected and Non Screen-detected colorectal cancer (patients undergoing a procedure with a curative intent)

\begin{tabular}{|c|c|c|c|c|}
\hline & $\begin{array}{c}\text { All } \\
\text { patients } \\
\text { n(\%) }\end{array}$ & $\begin{array}{c}\begin{array}{c}\text { Screen- } \\
\text { detected }\end{array} \\
\text { n(\%) }\end{array}$ & $\begin{array}{c}\text { Non } \\
\text { Screen- } \\
\text { detected } \\
\text { n(\%) }\end{array}$ & $p$-value \\
\hline & 872 & 393 & 479 & \\
\hline \multicolumn{5}{|l|}{ T-stage } \\
\hline $0 / 1$ & $233(27)$ & 149 (38) & $84(18)$ & \\
\hline 2 & $124(14)$ & $63(16)$ & $61(13)$ & \\
\hline 3 & $365(42)$ & 153 (39) & $212(44)$ & \\
\hline 4 & $150(17)$ & $28(7)$ & $122(26)$ & $<0.001$ \\
\hline \multicolumn{5}{|l|}{ N-stage ${ }^{1}$} \\
\hline $\mathbf{0}$ & $522(66)$ & 228 (69) & $294(64)$ & \\
\hline 1 & $182(23)$ & $73(22)$ & $109(24)$ & \\
\hline 2 & $89(11)$ & $32(10)$ & $57(12)$ & 0.138 \\
\hline \multicolumn{5}{|l|}{ Differentiation $^{2}$} \\
\hline Poor & $69(8)$ & $24(6)$ & $45(10)$ & \\
\hline Moderate/well & $795(92)$ & $368(94)$ & $427(90)$ & 0.066 \\
\hline \multicolumn{5}{|l|}{ Venous Invasion $^{3}$} \\
\hline Present & $405(50)$ & $163(44)$ & $242(55)$ & \\
\hline
\end{tabular}

This article is protected by copyright. All rights reserved. 


\begin{tabular}{|c|c|c|c|c|}
\hline Absent & $413(50)$ & $213(57)$ & $200(45)$ & 0.001 \\
\hline \multicolumn{5}{|c|}{ Peritoneal involvement ${ }^{1}$} \\
\hline Present & $128(16)$ & $20(6)$ & $108(24)$ & \\
\hline Absent & $665(84)$ & $313(94)$ & $352(77)$ & $<0.001$ \\
\hline \multicolumn{5}{|c|}{ Tumour Perforation 1} \\
\hline Present & $39(5)$ & $4(1)$ & $35(8)$ & \\
\hline Absent & $754(95)$ & $329(98)$ & $425(92)$ & $<0.001$ \\
\hline \multicolumn{5}{|c|}{ Margin Involvement ${ }^{1}$} \\
\hline Present & $27(3)$ & $5(2)$ & $22(5)$ & \\
\hline Absent & $766(97)$ & $328(98)$ & $438(95)$ & 0.012 \\
\hline \multicolumn{5}{|c|}{ Absolute neutrophil count ${ }^{4}$} \\
\hline$>7.5 \times 10^{9}$ & $70(9)$ & $13(4)$ & $57(13)$ & \\
\hline$<7.5 \times 10^{9}$ & $710(91)$ & $315(96)$ & $395(87)$ & $<0.001$ \\
\hline \multicolumn{5}{|c|}{ Neutrophil/lymphocyte ratio ${ }^{4}$} \\
\hline$>5$ & $123(16)$ & $28(9)$ & $95(21)$ & \\
\hline$<5$ & $657(84)$ & $300(91)$ & $357(79)$ & $<0.001$ \\
\hline
\end{tabular}

(1. $n=793$ resections, $2 . n=8663 . n=818.4 \cdot n=780$ )

This article is protected by copyright. All rights reserved. 
Table 3. Comparison of baseline characteristics (all patients) and tumour and host factors (patients managed with a curative intent) in patients with Interval and Screen-detected cancers

\begin{tabular}{|c|c|c|c|}
\hline & $\begin{array}{c}\text { Interval } \\
\text { n(\%) }\end{array}$ & $\begin{array}{c}\begin{array}{c}\text { Screen- } \\
\text { detected }\end{array} \\
\text { n(\%) }\end{array}$ & $p$-value \\
\hline & 182 & 421 & \\
\hline \multicolumn{4}{|l|}{ Age } \\
\hline$<64$ & $64(35)$ & $164(39)$ & \\
\hline $64-70$ & $59(32)$ & $114(27)$ & \\
\hline$>70$ & $59(32)$ & $143(34)$ & 0.765 \\
\hline \multicolumn{4}{|l|}{ Sex } \\
\hline Female & $91(50)$ & $142(34)$ & \\
\hline Male & $91(50)$ & $279(66)$ & $<0.001$ \\
\hline \multicolumn{4}{|l|}{ Site } \\
\hline Proximal to splenic flexure & $69(38)$ & $100(24)$ & \\
\hline Distal to splenic flexure & $113(62)$ & $321(76)$ & $<0.001$ \\
\hline Synchronous & 0 & 0 & \\
\hline \multicolumn{4}{|l|}{ TNM Stage } \\
\hline I & $37(20)$ & $191(45)$ & \\
\hline II & $45(25)$ & $93(22)$ & \\
\hline III & $53(29)$ & $103(25)$ & \\
\hline IV & $46(25)$ & $28(7)$ & $<0.001$ \\
\hline Unstaged & $1(1)$ & $6(1)$ & \\
\hline \multicolumn{4}{|l|}{ Management intent } \\
\hline Curative procedure & $130(71)$ & $393(93)$ & \\
\hline Palliative procedure & $20(11)$ & $8(2)$ & \\
\hline
\end{tabular}

This article is protected by copyright. All rights reserved. 


\begin{tabular}{|c|c|c|c|}
\hline No procedure & $32(18)$ & $20(5)$ & $<0.001$ \\
\hline \multicolumn{4}{|l|}{ T-stage ${ }^{1}$} \\
\hline $0 / 1 / 2$ & $43(33)$ & $212(54)$ & \\
\hline $3 / 4$ & $87(67)$ & $181(46)$ & $<0.001$ \\
\hline \multicolumn{4}{|l|}{ N-stage ${ }^{2}$} \\
\hline $\mathbf{0}$ & $77(61)$ & $228(69)$ & \\
\hline $1 / 2$ & $49(39)$ & $105(32)$ & 0.137 \\
\hline \multicolumn{4}{|l|}{ Differentiation $^{3}$} \\
\hline Poor & $13(10)$ & $24(6)$ & \\
\hline Moderate/well & $114(90)$ & $368(94)$ & 0.118 \\
\hline \multicolumn{4}{|l|}{ Venous Invasion 4} \\
\hline Present & $68(55)$ & $163(43)$ & \\
\hline Absent & $56(45)$ & $213(57)$ & 0.026 \\
\hline \multicolumn{4}{|c|}{ Absolute neutrophil count ${ }^{5}$} \\
\hline$>7.5 \times 10^{9}$ & $12(9)$ & $13(4)$ & \\
\hline$<7.5 \times 10^{9}$ & $115(91)$ & $315(96)$ & 0.021 \\
\hline \multicolumn{4}{|c|}{ Neutrophil/lymphocyte ratio 5} \\
\hline$>5$ & $20(16)$ & $28(9)$ & \\
\hline$<5$ & 107 (84) & 300 (91) & 0.025 \\
\hline
\end{tabular}

(1. $\mathrm{n}=523(100 \%)$ patients managed with a curative intent, $2 . \mathrm{n}=459$ resections, 3 . $\mathrm{n}=519(99 \%)$ patients managed with a curative intent, $4 . \mathrm{n}=500(96 \%)$ patients managed with a curative intent, $5 . n=455(87 \%)$ patients managed with a curative intent)

This article is protected by copyright. All rights reserved. 
Table 4. Comparison of baseline characteristics (all patients) and tumour and host factors (patients managed with a curative intent) in patients with Interval and Non-responder cancers

\begin{tabular}{|c|c|c|c|}
\hline & $\begin{array}{c}\text { Interval } \\
\text { n(\%) }\end{array}$ & $\begin{array}{c}\text { Non- } \\
\text { responder } \\
\text { n(\%) }\end{array}$ & p-value \\
\hline & 182 & 468 & \\
\hline \multicolumn{4}{|l|}{ Age } \\
\hline$<64$ & $64(35)$ & $188(40)$ & \\
\hline $64-70$ & $59(32)$ & $113(24)$ & \\
\hline$>70$ & $59(32)$ & $167(36)$ & 0.816 \\
\hline \multicolumn{4}{|l|}{ Sex } \\
\hline Female & $91(50)$ & $191(41)$ & \\
\hline Male & $91(50)$ & 277 (59) & 0.034 \\
\hline \multicolumn{4}{|l|}{ Site } \\
\hline Proximal to splenic flexure & $69(38)$ & $142(30)$ & \\
\hline Distal to splenic flexure & $113(62)$ & $317(68)$ & 0.090 \\
\hline Synchronous & 0 & $9(2)$ & \\
\hline \multicolumn{4}{|l|}{ TNM Stage } \\
\hline I & $37(20)$ & $74(16)$ & \\
\hline II & $45(25)$ & $130(28)$ & \\
\hline III & $53(29)$ & $115(25)$ & \\
\hline IV & $46(25)$ & 135 (29) & 0.052 \\
\hline Unstaged & $1(1)$ & $14(3)$ & \\
\hline \multicolumn{4}{|l|}{ Management intent } \\
\hline Curative procedure & $130(71)$ & $306(65)$ & \\
\hline Palliative procedure & $20(11)$ & $67(14)$ & \\
\hline
\end{tabular}

This article is protected by copyright. All rights reserved. 


\begin{tabular}{|c|c|c|c|}
\hline No procedure & $32(18)$ & $95(20)$ & 0.210 \\
\hline \multicolumn{4}{|l|}{ T-stage ${ }^{1}$} \\
\hline $0 / 1 / 2$ & $43(33)$ & $83(27)$ & \\
\hline $3 / 4$ & $87(67)$ & $223(73)$ & 0.210 \\
\hline \multicolumn{4}{|l|}{ N-stage ${ }^{2}$} \\
\hline $\mathbf{0}$ & $77(61)$ & $187(64)$ & \\
\hline $1 / 2$ & $49(39)$ & $105(36)$ & 0.569 \\
\hline \multicolumn{4}{|l|}{ Differentiation $^{3}$} \\
\hline Poor & $13(10)$ & $29(10)$ & \\
\hline Moderate/well & $114(90)$ & $273(90)$ & 0.840 \\
\hline \multicolumn{4}{|l|}{ Venous Invasion 4} \\
\hline Present & $68(55)$ & $157(56)$ & \\
\hline Absent & $56(45)$ & $121(44)$ & 0.761 \\
\hline \multicolumn{4}{|c|}{ Absolute neutrophil count ${ }^{5}$} \\
\hline$>7.5 \times 10^{9}$ & $12(9)$ & $41(15)$ & \\
\hline$<7.5 \times 10^{9}$ & $115(91)$ & $242(85)$ & 0.160 \\
\hline \multicolumn{4}{|c|}{ Neutrophil/lymphocyte ratio 5} \\
\hline$>5$ & $20(16)$ & $68(24)$ & \\
\hline$<5$ & $107(84)$ & $215(76)$ & 0.059 \\
\hline
\end{tabular}

(1. $n=436(100 \%)$ patients managed with a curative intent, $2 . n=418$ resections, 3 . $\mathrm{n}=429(98 \%)$ patients managed with a curative intent, $4 . \mathrm{n}=402(92 \%)$ patients managed with a curative intent, $5 . n=410(94 \%)$ patients managed with a curative intent)

This article is protected by copyright. All rights reserved. 
Figure 1

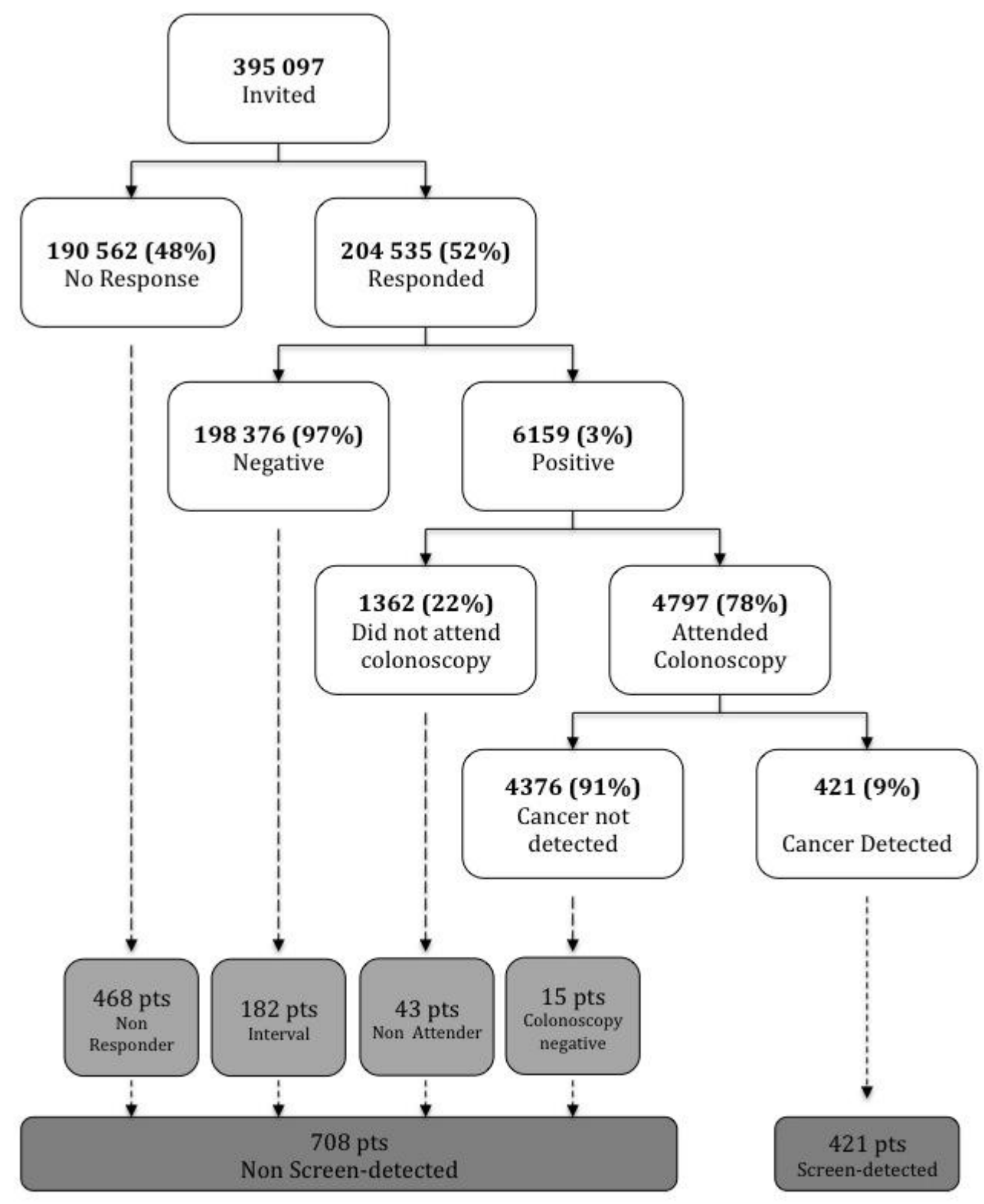

Figure 1: Outcome from the $1^{\text {st }}$ round of the Scottish Bowel Screening Programme in NHS Greater Glasgow \& Clyde (April 2009 to March 2011)

This article is protected by copyright. All rights reserved. 